\title{
Corrigenda: Epigean and hypogean Palaemonetes sp. (Decapoda, Palaemonidae) from Edwards Aquifer: An examination of trophic structure and metabolism. Subterranean Biology I4: 79-102.
}

\author{
Renee Bishop', William F. Humphreys'ㄹ, Glenn Longley ${ }^{3}$ \\ I Penn State University, 120 Ridge View Drive, Dunmore, PA, USA 2 Collections and Research Centre, \\ Western Australian Museum, Welshpool,WA6106, Australia; Australian Centre for Evolutionary Biology \\ and Biodiversity, and School of Earth and Environmental Sciences, The University of Adelaide, Adelaide, SA \\ 5005, Australia; School of Animal Biology, University of Western Australia, Nedlands, WA 6907, Australia \\ 3 Edwards Aquifer Research and Data Center, 248 Freeman Aquatic Building, 601 University Drive, San \\ Marcos, TX, USA
}

Corresponding author: Renee Bishop (reb20@psu.edu)

Academic editor: O. Moldovan | Received 22 February 2015 | Accepted 24 February 2015 | Published 12 June 2015

http://zoobank.org/2D9BC9E4-8FDD-4BC7-A3FE-82A96D832993

Citation: Bishop R, Humphreys W, Longley G (2015) Corrigenda: Epigean and hypogean Palaemonetes sp. (Decapoda, Palaemonidae) from Edwards Aquifer: An examination of trophic structure and metabolism. Subterranean Biology 14: 79-102. Subterranean Biology 15: 105-106. doi: 10.3897/subtbiol.15.4766

It has come to our attention that in the work referenced above the y-axis in Figure 1a and $1 \mathrm{c}$, should be $\delta 15 \mathrm{~N}$ and not $\delta 14 \mathrm{~N}$; the caption is correct.

The CORRECT figure is as follows:

Copyright Renee Bishop et al. This is an open access article distributed under the terms of the Creative Commons Attribution License (CC BY 4.0), which permits unrestricted use, distribution, and reproduction in any medium, provided the original author and source are credited. 

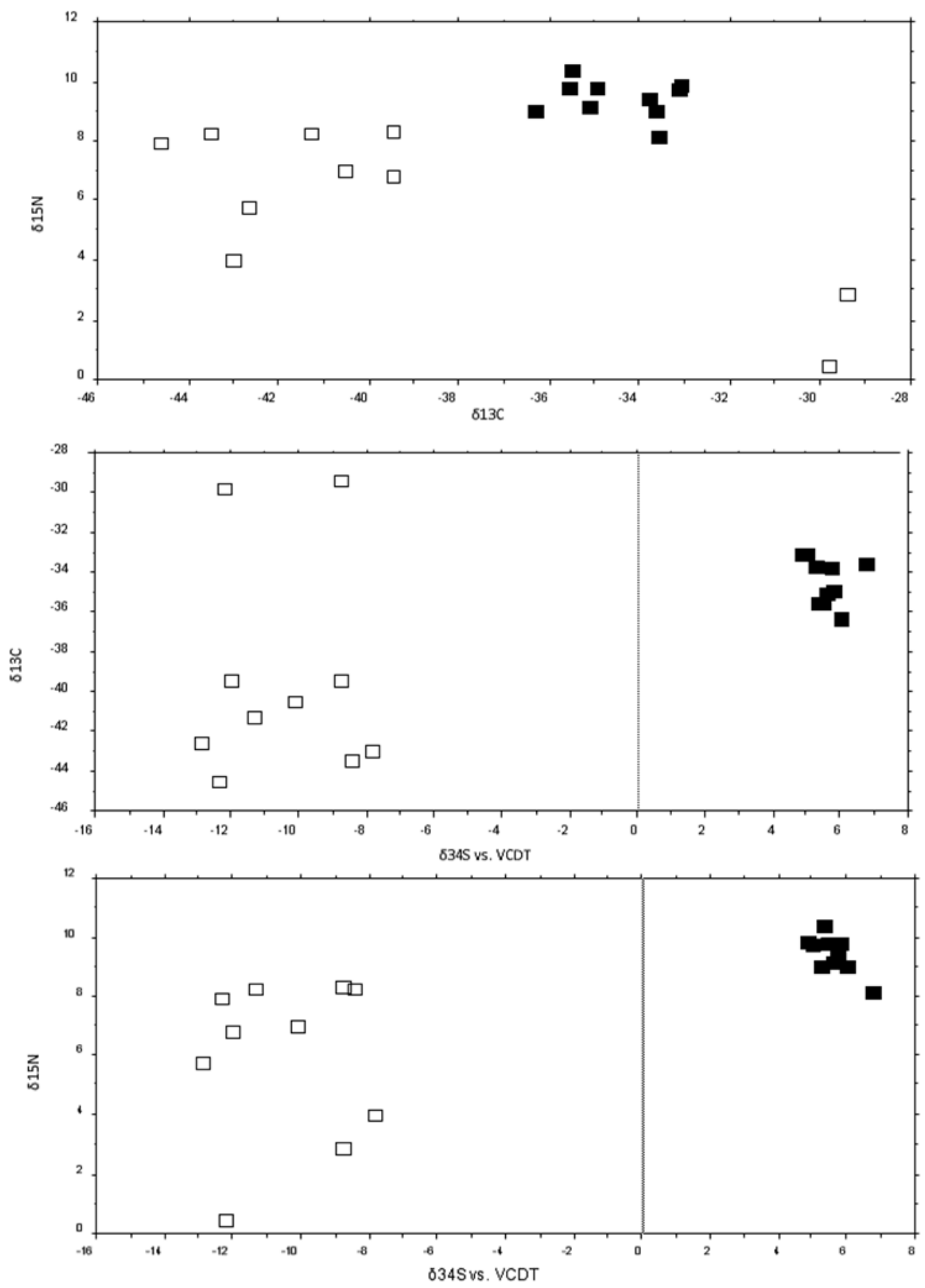